\title{
Shared decision-making in the context of unruptured intracranial aneurysms management
} Decisão médica compartilhada no contexto do tratamento dos aneurismas cerebrais não-rotos Luis Henrique de Castro-Afonso, Daniel Giansante Abud

\begin{abstract}
Shared decision-making practice has been encouraged in several clinical settings. In this model, clinical decisions are defined by doctors and patients based on the principle of patient autonomy. Shared decisions have been argued as an ethical clinical practice during complex and uncertain clinical situations. The best management of unruptured intracranial aneurysms (UIA) remains controversial. Despite the fact that shared decisions has probably been practiced, as far as we are aware it has not yet been evaluated, nor has it been standardized for patients presenting UIA. We aim to discuss possible roles, pros and cons of shared decision-making on the management of UIA.
\end{abstract}

Keywords: unruptured intracranial aneurysms, shared-decision making, intracranial aneurysms.

\section{RESUMO}

A decisão médica compartilhada tem sido estimulada em várias situações clínicas. Por este modelo, as decisões clínicas são definidas por pacientes e médicos em conjunto, baseado no princípio da autonomia dos pacientes. A decisão médica compartilhada tem sido apontada como uma prática ética para situações clínicas complexas ou incertas. O melhor manejo dos aneurismas cerebrais não rotos continua controverso. Apesar da decisão médica compartilhada ser provavelmente praticada, esta prática ainda não foi avaliada, nem padronizada, para o atendimento de pacientes com aneurisma cerebral não roto. Nós discutiremos os possíveis papéis da decisão médica compartilhada no manejo dos aneurismas cerebrais não rotos.

Palavras-chave: aneurismas cerebrais não rotos, decisão médica compartilhada, aneurismas cerebrais.

Shared decision-making practice has been encouraged in several clinical settings ${ }^{1,2,3,4,5,6}$. In this model, clinical decisions are defined by doctors and patients based on the principle of patient autonomy. After doctors provide technical and scientific information to patients, patients share their perspectives, beliefs and opinions regarding their conditions and treatments available with doctors, and finally, patients and doctors mutually make a final decision. The practice of shared decisions has been advocated because of its ethical fundamentals that take into account the autonomy of patients, which is particularly important in complex clinical scenarios where outcome predictions are unknown.

Despite the fact that shared decision-making has probably been practiced, as far as we are aware it has not yet been evaluated, nor has it been standardized for patients presenting unruptured intracranial aneurysms (UIA). Considering that shared decision-making has been argued to be an ethical and a reasonable clinical care practice, and the dynamics of the relationship between doctors and patients may be extremely variable, we aim to discuss possible roles, pros and cons of shared decision-making on the management of UIA.

\section{A SHARED DECISION-MAKING MODEL PROPOSAL}

We propose a new and simple grade system to classify the actual complex clinical scenario of UIA management based on shared decision-making practices ${ }^{5,6}$. First, we summarize a flowchart that includes the main paradigms of management of patients presenting UIA (Figure). Second, we divide doctors' indications and patients' intentions between four pretreatment clinical settings (Table). The doctors' indications were divided into two categories: the first is when the doctor indicates invasive treatment and the second is when the doctor indicates medical management. The patients' perspectives were divided between two groups. The first group consists of patients prone to choosing invasive treatment, and the second group consists of patients prone to choosing 
medical management. From the doctor indications and patient preferences mentioned above, four pretreatment settings were identified (Table). These four settings will result in one of three possible final decisions. The final decisions are (A) an invasive treatment, (B) medical management and (C) a definitive disagreement between doctor and patient. Pretreatment settings I and IV may result in decisions A and $\mathrm{B}$, respectively, whereas settings II and III may result in decision C, or A, or B as well. Patients that choose decision $\mathrm{C}$ may look for other expert opinions.

\section{THE VALUE OF SHARED DECISION-MAKING IN THE CONTEXT OF UIA}

Shared decisions widely differ from the paternalist model, where clinical decisions are centered on doctors. In that model, only doctors hold the necessary scientific knowledge and expertise to make a final decision about the treatment of patients, while patients play a passive role in clinical decisions. In the paternalistic model, doctors offer scientific knowledge and technical expertise for patients. However, in addition to scientific aspects, patients have their own perspectives, values and beliefs about their clinical conditions and treatments available. The proponents of shared decisions argue that the paternalistic model does not take into account patients' autonomy on their treatment. The following definition

Table. Pretreatment clinical settings.

\begin{tabular}{lll}
\hline & $\begin{array}{c}\text { Group of patients divided by their } \\
\text { treatment preferences }\end{array}$ \\
\hline $\begin{array}{l}\text { Operator's indication } \\
\text { Invasive treatment }\end{array}$ & Invasive treatment & Medical management \\
Medical management & III
\end{tabular}

disagreement between parts

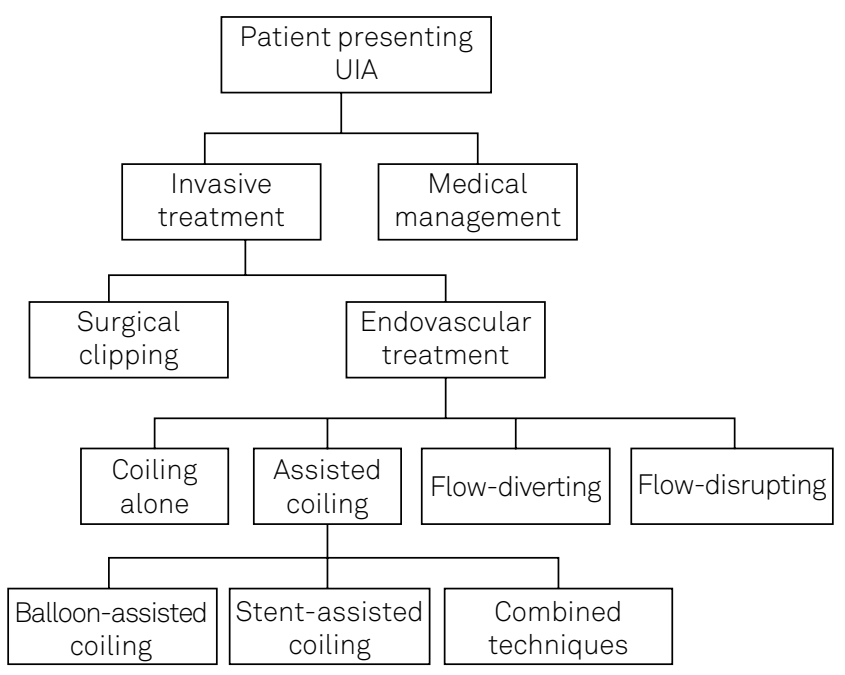

Figure. Flowchart of the management of patients presenting UIA. of shared decisions is an interesting conjecture described by Quill et al on this theme ${ }^{7}$.

"Final choices belong to patients, but these choices gain meaning, richness, and accuracy if they are the result of a process of mutual influence and understanding between physician and patient" ${ }^{\text {" }}$.

The best management of UIA remains controversial, mainly because best scientific data, which come from randomized trials, are lacking. In a first encounter between doctor and patient presenting an UIA, both doctor and patient often face unresolved dilemmas about the treatment of UIA. The first dilemma is about conservative versus invasive treatment. If an invasive treatment is chosen, other questions emerge regarding which is the best invasive approach (surgical or endovascular). Moreover, when the endovascular treatment is indicated, there are described several strategies to achieve treatment of UIA (Figure). Currently, scientific data from randomized trials are not available to guide doctors and patients to solve all questions and dilemmas mentioned above.

Controversies on best management of UIA can be observed by assessing doctors' indications on UIA management. Interventional neuroradiologists and neurosurgeons usually rely on variables like patient age, operative risk factors, aneurysm size, morphology, location, growth rate, and intra-aneurysmal flow patterns to support their decisions regarding UIA management. However, substantial disagreement between doctors on management of UIA has been recently reported $^{8,9,10}$, which suggests that doctors are not absolutely or uniformly sure about their beliefs on the management of UIA.

Concerning scientific attempts to solve the problem of aneurysm management, several studies have proposed probabilistic decision models to aid doctors in their choices, including decision trees and score risks ${ }^{11,12,13,14,15}$. A recent interesting study, proposed a mathematical score (the PHASES score) to predict the 5-year rupture risk of UIA. Constructed based on a pooled analysis of six large UIA prospective cohorts studies including 8382 patients, the PHASES risk score comprises six predictors: age, arterial hypertension, previous subarachnoid hemorrhage, aneurysm size, aneurysm location, and geographical region. The PHASES score range from 0 to 22 points and the 5-year risk of aneurysm rupture range from 0.4 to $17.8 \%^{16}$. However, studies designed to predict aneurysm rupture risk, and to guide clinical decisions, have been exhaustively criticized mainly because most of prediction models were based on data extracted of observational cohorts, which have important selection bias and, thus, do not reliably represents all patients presenting UIA ${ }^{17,18,19,20,21,22,23}$. In this context, risk prediction models are probably misleading tools to support clinical decision-making.

Shared decisions have been argued as a good practice during complex and uncertain clinical situations, wherein the best clinical management is not yet known, and its 
benefit has not yet been adequately proven. As the best management of UIA is unknown, shared decisions may prevent unilateral decisions by paternalistic doctors or may help doctors and patients share the hard responsibility to make a difficult decision in a context of uncertainty. In addition, compared to the paternalistic model, shared decisions may play an important role in preventing lawsuits in the setting of treatment-related complications.

Concerning the scientific value of shared decisions, the current scientific method used for clinical research is based on hypothesis verification by means of clinical experiments and the final results obtained may prove or contest and redefine the initial hypothesis ${ }^{24}$. Because of the subjective desires of patients and the variable indications of doctors ${ }^{8,9,10}$, we do not believe that a shared decision-making classification system, as described above, could generate specific scientific hypothesis for randomized trials. Nevertheless, whether study's results could be influenced by shared decisions before enrollment in trials is unknown, and it has to be demonstrated. Unfortunately, randomization has been reported to be difficult to achieve in the setting of UIA management ${ }^{25}$, and currently, most of the studies published on UIA treatment have a nonrandomized design.

On the other hand, shared decision-making may influence results of nonrandomized studies, because patients' and doctors' decisions may play an important role in achieving imbalances between groups, which are explained by the following examples. First, high-risk and older patients may be prone to deciding in favor of medical management, whereas young and healthy patients may favor invasive treatment. Second, the availability of a minimally invasive treatment may influence patients to decide against medical management and choose embolization rather than clipping. Third, doctors may indicate invasive treatment for the young and healthy patients, and the medical management for older and high-risk patients. Fourth, doctors may indicate endovascular treatment for older patients presenting large aneurysms, and indicate clipping for young and healthy patients. Therefore, a survey of the factors influencing doctors and patients on final decisions could explain the distribution of baseline variables or investigate what is the role of patients and doctors is in the increasing indications of endovascular treatment for UIA ${ }^{26}$ (Table).

The practice of shared decision-making in daily clinical practice should make doctors and patients aware that they have been making clinical choices in obscure scientific environments. Therefore, such a practice may stimulate doctors and patients to participate in clinical trials.

\section{PROBLEMS OF SHARED DECISION-MAKING IN THE CONTEXT OF UIA}

The principle of autonomy is a central issue in shared decisions practice. However, autonomy presupposes competency, rational desires, and above all, reliable knowledge ${ }^{27}$. From that point of view, valid scientific knowledge is essential for a true shared decision-making practice, which is the problem of UIA care, where scientific data is scarce, incomplete and unreliable. Therefore, the lack of valid information about UIA management may increase the subjectivity and the scientific imprecision of shared decision-making.

Another fundamental issue about shared decisions for UIA management is to block scientific data acquisition. It is possible that shared decisions influence doctors to feel ethically comfortable during their daily clinical decisions on UIA management. If doctors feel comfortable in their decisions, research on UIA would be compromised because it could reduce doctors' interest in enrolling patients in trials.

\section{FINAL REMARKS}

Shared decision-making is considered an ethical way to deal with patients in daily clinical care. However, in the context of UIA care, shared decision-making practice should not be a justification to doctors feel ethically comfortable about their decisions. We believe that a scientific value of shared decision-making practice may be to arouse doctors and patients about the lack of reliable data on UIA management, and thus to encourage all to participate in clinical trials.

\section{References}

1. Mulley AG, Trimble C, Elwyn G. Stop the silent misdiagnosis: patients' preferences matter. BMJ. 2012;345:e6572. doi:10.1136/bmj.e6572

2. Marshall M, Bibby J. Supporting patients to make the best decisions. BMJ. 2011;342:d2117. doi:10.1136/bmj.d2117

3. Flynn D, Knoedler MA, Hess EP, Murad MH, Erwin PJ, Montor

$\mathrm{VM}$ et al. Engaging patients in health care decisions in the emergency department through shared decision-making: a systematic review. Acad Emerg Med. 2012;19(8):959-67. doi:10.1111/j.1553-2712.2012.01414.x

4. Stacey D, Bennett CL, Barry MJ, Col NF, Eden KB, Holmes-Rovner $M$ et al. Decision aids for people facing health treatment or screening decisions. Cochrane Database Syst Rev. 2011;(10):CD001431. doi:10.1002/14651858.CD001431.pub3

5. Charles C, Gafni A, Whelan T. Decision-making in the physician-patient encounter: revisiting the shared treatment decision-making model. Soc Sci Med. 1999;49(5):651-61. doi:10.1016/S0277-9536(99)00145-8

6. Brock DW. The ideal of shared decision making between physicians and patients. Kennedy Inst Ethics J. 1991;1(1):28-47. doi:10.1353/ken.0.0084

7. Quill TE, Brody H. Physician recommendations and patient autonomy: finding a balance between powerand patient choice. Ann Intern Med. 1996;125(9):763-9. doi:10.7326/0003-4819-125-9-199611010-00010 
8. Etminan N, Beseoglu K, Barrow DL, Bederson J, Brown RD $J r$, Connolly ES Jr et al. Multidisciplinary consensus on assessment of unruptured intracranial aneurysms: proposal of an International Research Group. Stroke. 2014;45(5):1523-30. doi:10.1161/STROKEAHA.114.004519

9. Darsaut TE, Estrade L, Jamali S, Bojanowski MW, Chagnon M, Raymond J. Uncertainty and agreement in the management of unruptured intracranial aneurysms. J Neurosurg. 2014;120(3):618-23. doi:10.3171/2013.11.JNS131366

10. Darsaut TE, Gentric JC, McDougall CM, Gevry G, Roy D, Weill A et al Uncertainty and Agreement Regarding the Role of Flow Diversion in the Management of Difficult Aneurysms. AJNR Am J Neuroradiol. 2015;36(5):930-6. doi:10.3174/ajnr.A4201

11. Ghinea N, van Gelder JM. A probabilistic and interactive decision-analysis system for unruptured intracranial aneurysms. Neurosurg Focus. 200415;17(5):E9. doi:10.3171/foc.2004.17.5.9

12. Takao H, Nojo T, Ohtomo K. Cost-effectiveness of treatment of unruptured intracranial aneurysms in patients with a history of subarachnoid hemorrhage. Acad Radiol. 2008;15(9):1126-32. doi:10.1016/j.acra.2008.02.017

13. Greving JP, Rinkel GJ, Buskens E, Algra A. Cost-effectiveness of preventive treatment of intracranial aneurysms: new data and uncertainties. Neurology. 2009;73(4):258-65. doi:10.1212/01.wnl.0b013e3181a2a4ea

14. Takao H, Nojo T. Treatment of unruptured intracranial aneurysms: decision and cost-effectiveness analysis. Radiology. 2007;244(3):755-66. doi:10.1148/radiol.2443061278

15. Yoshimoto Y. A mathematical model of the natural history of intracranial aneurysms: quantification of the benefit of prophylactic treatment. J Neurosurg. 2006;104(2):195-200. doi:10.3171/jns.2006.104.2.195

16. Greving JP, Wermer MJ, Brown RD Jr, Morita A, Juvela S, Yonekura $M$ et al. Development of the PHASES score for prediction of risk of rupture of intracranial aneurysms: a pooled analysis of six prospective cohort studies. Lancet Neurol. 2014;13(1):59-66. doi:10.1016/S1474-4422(13)70263-1

17. Naggara O, Darsaut T, Trystram D, Tselikas L, Raymond. Unruptured intracranial aneurysms: why we must not perpetuate the impasse for another 25 years. Lancet Neurol. 2014;13(6):537-8. doi:10.1016/S1474-4422(14)70091-2

18. Raymond J, Molyneux AJ, Takao H, Nojo T, Ohtomo K. Unruptured intracranial aneurysms: evidence and speculations. Radiology. 2008;247(1):294. doi:10.1148/radiol.2471071662

19. Raymond J, Darsaut TE, Molyneux AJ; TEAM collaborative Group. A trial on unruptured intracranial aneurysms (the TEAM trial): results, lessons from a failure and the necessity for clinical care trials. Trials. 2011 Mar 4;12:64. doi:doi:10.1186/1745-6215-12-64

20. Raymond J, Guillemin F, Proust F, Molyneux AJ, Fox AJ, Claiborne JS et al. Unruptured Intracranial aneurysms. A critical review of the international study of unruptured intracranial aneurysms (ISUIA) and of appropriate methods to address the clinical problemm. Interv Neuroradiol. 2008;14(1):85-96. doi:10.1177/159101990801400111

21. Raymond J, Darsaut TE, Kotowski M, Bojanowski MW. Unruptured intracranial aneurysms: why clinicians should not resort to epidemiologic studies to justify interventions. AJNR Am J Neuroradiol. 2011;32(9):1568-9. doi:10.3174/ajnr.A2764

22. Raymond J, Roy D, Weill A, Guilbert F, Nguyen T, Molyneux AJ et al. Unruptured intracranial aneurysms: their illusive natural history and why subgroup statistics cannot provide normative criteria for clinical decisions or selection criteria for a randomized trial.J Neuroradiol. 2008;35(4):210-6. doi:10.1016/j.neurad.2007.12.001

23. Raymond J. Managing unruptured aneurysms: the ethical solution to the dilemma. Can J Neurol Sci. 2009;36(2):138-42. doi:10.1017/S0317167100006491

24. Popper K. Logik der Forschung. Vienna: Springer; 1959.

25. Raymond J, Darsaut TE, Molyneux AJ. A trial on unruptured intracranial aneurysms (the TEAM trial): results, lessons from a failure and the necessity for clinical care trials. Trials. 2011;12(1):64. doi:10.1186/1745-6215-12-64

26. Lin N, Cahill KS, Frerichs KU, Friedlander RM, Claus EB. Treatment of ruptured and unruptured cerebral aneurysms in the USA: a paradigm shift. J Neurointerv Surg. 2012;4(3):182-9. doi:10.1136/jnis.2011.004978

27. Savulescu J. Rational desires and the limitation of life-sustaining treatment. Bioethics. 1994;8(3):191-222. doi:10.1111/j.1467-8519.1994.tb00255.x 